\title{
PD-L1 expression as poor prognostic factor in patients with non- squamous non-small cell lung cancer
}

\author{
Cuiling Zhou ${ }^{1, *}$, Jianjun Tang ${ }^{2, *}$, Huanhuan Sun ${ }^{1, *}$, Xiaobin Zheng ${ }^{3}$, Zhanyu $\mathbf{L i}^{4}$, \\ Tiantian Sun ${ }^{5}$, Jie $\mathrm{Li}^{6}$, Shuncong Wang ${ }^{1}$, Xiuling Zhou ${ }^{1}$, Hongliu Sun ${ }^{7}$, Zhibin Cheng ${ }^{1}$, \\ Hongyu Zhang ${ }^{1}$ and Haiqing $\mathrm{Ma}^{1}$ \\ ${ }^{1}$ Department of Oncology, The Fifth Affiliated Hospital of Sun Yat-sen University, Zhuhai, Guangdong 519000, China \\ ${ }^{2}$ Department of Gastroenterology, Cancer Hospital of Jiangxi Province, Nanchang, Jiangxi 330029, China \\ ${ }^{3}$ Department of Respiration, The Fifth Affiliated Hospital of Sun Yat-sen University, Zhuhai, Guangdong 519000, China \\ ${ }^{4}$ Department of Pathology, The Fifth Affiliated Hospital of Sun Yat-sen University, Zhuhai, Guangdong 519000, China \\ ${ }^{5}$ Department of Hematology, The First Affiliated Hospital of Sun Yat-sen University, Guangzhou, Guangdong 510080, China \\ ${ }^{6}$ Department of Breast and Thyroid Surgery, The First Affiliated Hospital of Sun Yat-sen University, Guangzhou, Guangdong \\ 510080, China \\ ${ }^{7}$ Department of Pathology, University of Michigan, Ann Arbor, MI 48201, USA \\ *These authors have contributed equally to this work \\ Correspondence to: Haiqing Ma, email: mahaiqing@mail.sysu.edu.cn \\ Hongyu Zhang, email: zdwyzhy@163.com \\ Keywords: NSCLC, PD-L1, survival, prognostic factor, histologic type
}

Received: August 29, $2016 \quad$ Accepted: March 22, $2017 \quad$ Published: April 11, 2017

Copyright: Zhou et al. This is an open-access article distributed under the terms of the Creative Commons Attribution License 3.0 (CC BY 3.0), which permits unrestricted use, distribution, and reproduction in any medium, provided the original author and source are credited.

\section{ABSTRACT}

Objectives: The role of programmed cell death ligand 1 (PD-L1) in non-small cell lung cancer (NSCLC), especially according to histologic type, remains controversial. The purpose of this study was to assess PD-L1 expression and its association with overall survival (OS) and clinicopathologic characteristics in NSCLC.

Materials and methods: Formalin-fixed paraffin-embedded specimens were obtained from 108 patients with surgically resected primary NSCLC. PD-L1 expression was assessed via immunohistochemistry using a histochemistry score system. The relationship between OS or clinicopathologic characteristics and PD-L1 expression was evaluated via the Kaplan-Meier method and Cox proportional hazards model, respectively.

Results: Of 108 NSCLC specimens, 44 had high PD-L1 expression, which was highly associated with histologic type $(p=0.003)$. Patients without PD-L1 expression had remarkably longer OS than those with PD-L1 expression (median OS: 96 months vs. 33 months, $p<0.001$ ). In the subgroup analysis of non-squamous cell carcinoma, OS was more favorable in those without PD-L1 expression than in those with PD-L1 expression (median OS: 113 months vs. 37 months, $p<0.001$ ). Multivariate analysis revealed that PD-L1 expression (95\% confidence interval 1.459-4.520, $p<0.001$ ), male sex and higher tumor-node-metastasis stage were significantly correlated with shorter OS.

Conclusions: This study demonstrated that PD-L1 expression is an independent prognostic factor for poor survival in NSCLC patients, especially those with nonsquamous NSCLC. 


\section{INTRODUCTION}

Lung cancer is the leading cause of cancer death worldwide [1]. Although in recent years multidisciplinary therapies have been widely used in patients with nonsmall cell lung cancer (NSCLC), the overall prognosis of NSCLC remains poor. Previous studies expressed full confidence in the promising prospects of monoclonal antibodies, which can effectively block inhibitory immune checkpoints, among the various immunotherapeutic strategies in lung cancer [2-4]. Preclinical and clinical data showed that monoclonal antibodies can significantly enhance the antitumor immunity of patients [3].

Cytotoxic T-lymphocyte-associated antigen 4 (CTLA-4), a second counter receptor for the B7 family of co-stimulatory molecules, was the first clinically validated checkpoint pathway target. CTLA-4 inhibits T cell activation in initial stages and breaks tolerance of human cancer antigens, many of which are normal self-antigens, yet produces frequent immune-related adverse events [5-7]. More recently, programmed death $1 /$ programmed cell death ligand-1 (PD-1/PD-L1) has become a popular blockade of co-inhibitory immune pathways. PD-1 (also known as CD279), a member of the CD28 family, is expressed on many lymphocytes and negatively regulates their proliferation and activation, such as activated $\mathrm{T}$ cells, regulatory $\mathrm{T}$ cells, and B-cells [8, 9]. PD-1 has two binding ligands, PD-L1 (B7-H1, CD274) and programmed cell death ligand-2 (PD-L2, B7-DC, CD273), both of which belong to the B7 family [10-12]. PD-L2 is mainly expressed on activated dendritic cells and macrophages. PD-L1 is not only broadly expressed on non-immune cells, such as T cells, B cells, macrophages, and dendritic cells, but it is also upregulated after their activation. Furthermore, researchers have recently discovered the expression of PD-L1 in various tumor cells, including breast cancer, gastric cancer, NSCLC, pancreatic cancer, bladder cancer, cervical cancer, renal cell carcinoma, and melanoma [13-20]. The inhibition of the PD-1/PD-L1 pathway enhances antitumor immunity to prevent tumor cells from escaping from host immune responses, thus providing a promising strategy for specific tumor immunotherapy [21].

Nonetheless, data on the prognostic role of PDL1 expression in NSCLC tumor cells and its correlation with clinicopathologic characteristics are conflicting. Two previous studies showed that PD-L1 expression was a favorable prognostic factor for overall survival (OS) in NSCLC $[22,23]$. However, several meta-analyses indicated that PD-L1 expression was associated with poor OS in NSCLC patients, yet the association of PDL1 expression with clinicopathologic characteristics, especially histologic type, remained unclear [24-26].

In this study, we used immunohistochemistry (IHC) to assess the prognostic role of PD-L1 in the OS of patients with surgically resected NSCLC and the association between PD-L1 expression and clinicopathologic characteristics, including histologic type, sex, age, and pathologic tumor-node-metastasis (TNM) stage.

\section{RESULTS}

\section{Patient characteristics}

A total of 108 patients with NSCLC were included in the study. The patients' characteristics are shown in Table 1. All patients underwent surgical resection when first diagnosed with primary NSCLC. The mean follow-up after surgical resection was 48.4 months. The median age of the patients at diagnosis was 55 years (range, $15-75$ years), and $59 \%$ were male. In our enrolled NSCLC patients, TNM stages I, II, III, and IV at initial diagnosis were identified in $39,26,36$, and 6 patients, respectively. The tumor grade of one tumor sample was not reported. The tumor histology was squamous cell carcinoma in 34 specimens, adenocarcinoma in 57 specimens, adenosquamous carcinoma in 11 specimens, and other histologic types in 6 specimens.

\section{Correlations of PD-L1 expression and clinicopathologic characteristics}

Of the 108 cases of NSCLC, 44 had PD-L1 expression in the tumor cell membrane and cytoplasm. Squamous cell carcinomas and adenocarcinomas with PDL1 staining are shown in Figures 1 and 2.

The correlation of PD-L1 expression with clinicopathologic characteristics is presented in Table 2 . PD-L1 expression was significantly associated with histologic type ( $p=0.003$ ). The percentage of PD-L1positive cells in squamous cell carcinoma was higher than that in non-squamous cell carcinoma (62.8\% vs. $31.1 \%$ ), whereas, the absence of PD-L1 expression was more common in non-squamous cell carcinoma than in squamous cell carcinoma ( $68.9 \%$ vs. $38.2 \%$ ). In contrast, PD-L1 expression was not significantly correlated with sex $(p=0.408)$, age $(p=0.596)$, TNM stage $(p=0.134)$, tumor stage $(p=0.240)$, node metastasis $(p=0.061)$, or the degree of differentiation ( $p=0.065)$.

\subsection{PD-L1 expression and OS}

In Figure 3, the Kaplan-Meier curves revealed that patients whose tumors did not have PD-L1 expression had significantly longer OS than those with PD-L1 expression (median OS: 96 months vs. 33 months, $p<0.001$ ).

In univariate analysis, the risk of death was significantly higher in those with PD-L1 expression than in those without PD-L1 expression (95\% conference interval (CI), 1.355-3.840, $p=0.002)$. Similar results were observed in those who were male, had a higher TNM stage, had a greater degree of node metastasis, and had squamous cell carcinoma (Table 3). In multivariate analysis, PD-L1 expression (hazerd ratio $(\mathrm{HR})=2.568$, $95 \%$ CI, 1.459-4.520, $p<0.001)$, male sex $(\mathrm{HR}=2.236$, $95 \% \mathrm{CI}, 1.236-4.047, p=0.008$ ), and higher TNM stage $(\mathrm{HR}=2.416,95 \% \mathrm{CI}, 1.402-4.164, p=0.001)$ remained independent risk predictors for poorer OS (Table 3 ). 
Table 1: Patient characteristics

\begin{tabular}{|c|c|c|}
\hline Characteristic & No. of patients & $\%$ \\
\hline \multicolumn{3}{|l|}{ Sex } \\
\hline Male & 64 & 59.3 \\
\hline Female & 44 & 40.7 \\
\hline \multicolumn{3}{|l|}{ Age (in years) } \\
\hline$<60$ & 63 & 58.3 \\
\hline$\geq 60$ & 45 & 41.7 \\
\hline \multicolumn{3}{|l|}{ TNM stage } \\
\hline I & 39 & 36.5 \\
\hline II & 26 & 24.3 \\
\hline III & 36 & 33.6 \\
\hline IV & 6 & 5.6 \\
\hline \multicolumn{3}{|l|}{ Tumor stage } \\
\hline pT1 & 17 & 16.0 \\
\hline pT2 & 58 & 54.7 \\
\hline pT3 & 27 & 25.5 \\
\hline pT4 & 4 & 3.8 \\
\hline \multicolumn{3}{|l|}{ Node metastasis } \\
\hline $\mathrm{pN} 0$ & 65 & 63.1 \\
\hline $\mathrm{pN} 1$ & 11 & 10.7 \\
\hline $\mathrm{pN} 2$ & 27 & 26.2 \\
\hline \multicolumn{3}{|l|}{ Histologic type } \\
\hline Squamous cell carcinoma & 34 & 31.4 \\
\hline Adenocarcinoma & 57 & 52.8 \\
\hline Adenosquamous carcinoma & 11 & 10.2 \\
\hline Other & 6 & 5.6 \\
\hline \multicolumn{3}{|l|}{ Differentiation degree } \\
\hline Poorly differentiated & 20 & 22.2 \\
\hline Moderately differentiated & 62 & 68.9 \\
\hline Highly differentiated & 8 & 8.9 \\
\hline \multicolumn{3}{|l|}{ PD-L1 expression } \\
\hline Negative & 64 & 59.3 \\
\hline Positive & 44 & 40.7 \\
\hline
\end{tabular}

Subgroup analyses revealed that OS was more favorable in those without PD-L1 expression than in those with PD-L1 expression among males (median OS: 55 months vs. 26 months, $p<0.001$ ) and patients of different age groups ( $<60, p=0.013 ; \geq 60, p=0.040$, respectively), but not among females (median OS: 103 months vs. 98 months, $p=0.195$ ) (Figure 4). Subgroup analyses also showed that OS was more favorable in those without PD-L1 expression than in those with PD-L1 expression among patients with TNM stage I/II disease (median OS: 103 months vs. 55 months, $p=0.036$ ), TNM stage III/ IV disease (median OS: 58 months vs. 26 months, $p=$ 0.005 ), and tumor stage pT3 (median OS: 96 months vs. 26 months, $p=0.005)$, but not in patients with tumor stage pT1, pT2, or pT4 or node metastasis $(p>0.05)$ (Figure 5). Interestingly, in the subgroup analysis of non-squamous cell carcinoma, OS was more favorable in those without PD-L1 expression than in those with PD-L1 expression 
(median OS: 113 months vs. 37 months, $p<0.001$ ). However, subgroup analysis of squamous cell carcinoma did not reveal any significant difference in OS between those without PD-L1 expression and those with PD-L1 expression (median OS: 44 months vs. 27 months, $p=$ $0.619)$. Similarly, there was no significant difference based on the degree of differentiation $(p>0.05)$ (Figure 6).

\section{DISCUSSION}

This study demonstrated that PD-L1 expression is an independent prognostic factor for poor OS in NSCLC patients, especially those with non-squamous NSCLC.
The analysis also confirmed that high PD-L1 expression is significantly associated with histologic type.

We further demonstrated that patients without PD-L1 expression had significantly longer OS than those with PD-L1 expression. Previous studies similarly reported that high PD-L1 expression was regarded as a poor prognostic biomarker in patients with lung cancer, renal cell carcinoma, breast cancer, malignant melanoma, hepatocellular carcinoma, gastric carcinoma, pancreatic cancer, and ovarian cancer [13, 27-34]. Another study reported that no association was found between PD-L1 overexpression and 3-year overall OS of lung cancer [35]. Using different clone of PD-L1 antibodies as well as different tricks of immunohistochemical technology in the
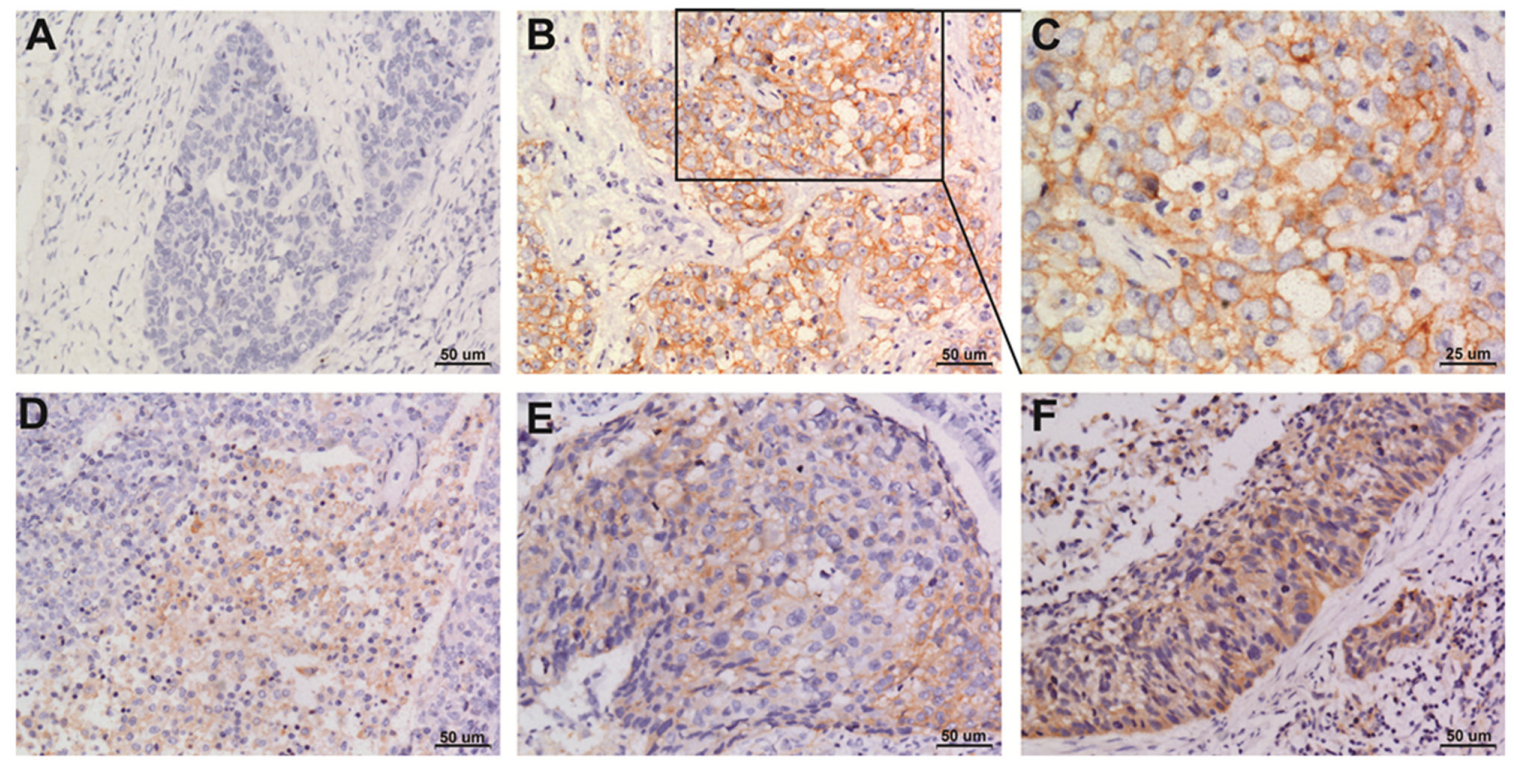

Figure 1: Representative images of PD-L1 staining in squamous cell NSCLC (A) negative; (B and C) positive; (D-F) weak positive, moderate positive, strong positive. Original magnification: A, B, D, E, F panels x 200, C panel x 400.
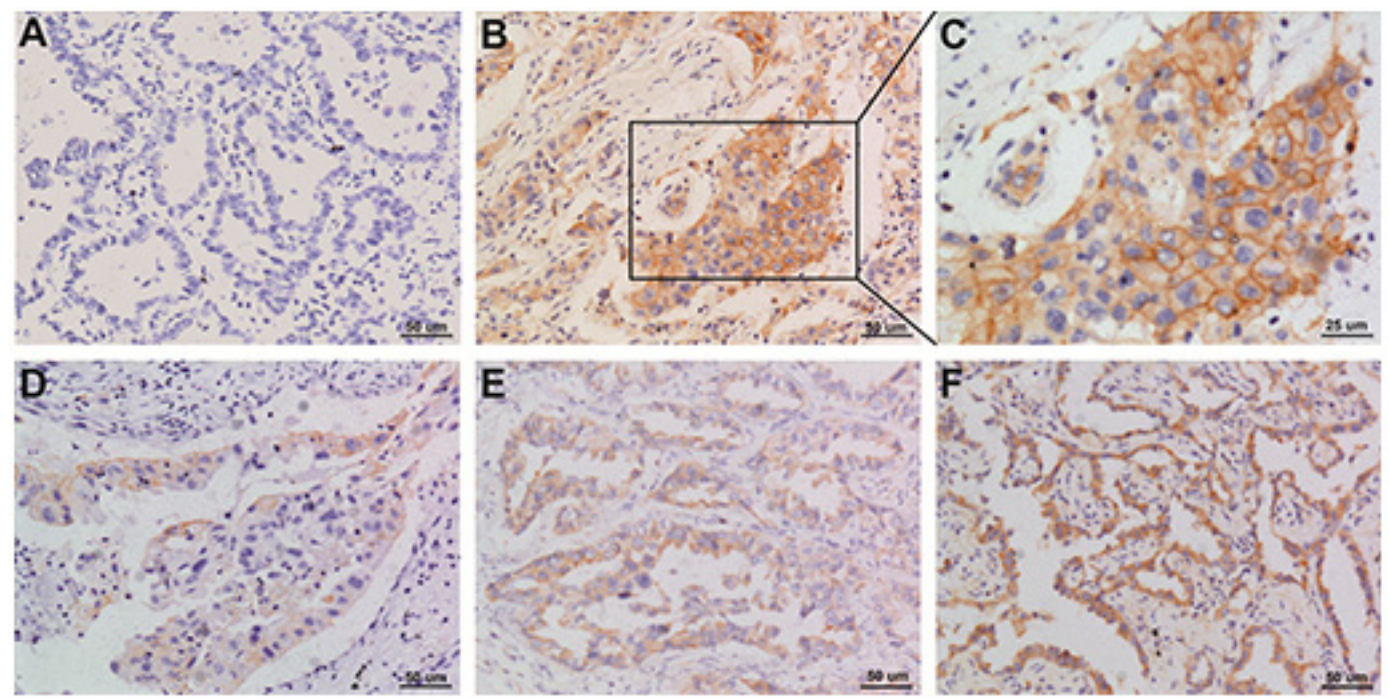

Figure 2: Representative images of PD-L1 staining in adenocarcinoma NSCLC (A) negative; (B and C) positive; (D-F) weak positive, moderate positive, strong positive. Original magnification: A, B, D, E, and F panels x 200, C panel x 400. 
Table 2: Patients characteristics and their association with PD-L1 expression

\begin{tabular}{|c|c|c|c|}
\hline Characteristic & Negative, n (\%) & Positive, n (\%) & $p$ Value \\
\hline Sex & & & 0.408 \\
\hline Male & $40(62.5)$ & $24(37.5)$ & \\
\hline Female & $24(54.5)$ & $20(45.5)$ & \\
\hline Age (in years) & & & 0.596 \\
\hline$<60$ & $36(57.1)$ & $27(42.9)$ & \\
\hline$\geq 60$ & $28(62.2)$ & $17(37.8)$ & \\
\hline TNM stage & & & 0.134 \\
\hline $\mathrm{I} / \mathrm{II}$ & $42(64.6)$ & $23(35.4)$ & \\
\hline III/IV & $21(50.0)$ & $21(50.0)$ & \\
\hline Tumor stage & & & 0.240 \\
\hline pT1 & $13(76.5)$ & $4(23.5)$ & \\
\hline pT2 & $33(56.9)$ & $25(43.1)$ & \\
\hline pT3 & $16(59.3)$ & $11(40.7)$ & \\
\hline pT4 & $1(25.0)$ & $3(75.0)$ & \\
\hline Node metastasis & & & 0.061 \\
\hline pN0 & $43(66.2)$ & $22(33.8)$ & \\
\hline $\mathrm{pN} 1 / \mathrm{pN} 2$ & $18(47,4)$ & $20(52.6)$ & \\
\hline Histologic type & & & 0.003 \\
\hline Squamous cell carcinoma & $13(38.2)$ & $21(62.8)$ & \\
\hline $\begin{array}{l}\text { Non-squamous cell } \\
\text { carcinoma }\end{array}$ & $51(68.9)$ & $23(31.1)$ & \\
\hline Differentiation degree & & & 0.065 \\
\hline Poorly differentiated & $8(40.0)$ & $12(60.0)$ & \\
\hline Moderately differentiated & $38(61.3)$ & $24(38.7)$ & \\
\hline Highly differentiated & $7(87.5)$ & $1(12.5)$ & \\
\hline
\end{tabular}

included studies may contribute to the conflicting results. However, further studies are needed to confirm the impact of antibodies on the results of studies.

The PD-1/PD-L1 axis is an inhibitory signaling pathway that gives rise to T-cell exhaustion and inactivation, thus preventing an autoimmune response. PD-L1 expression has also been demonstrated to be related to response to various anti-PD-1/PD-L1 antibodies [36-38]. The phase 3 study CheckMate 057 demonstrated that treatment with nivolumab, the first anti-PD-1 antibody, significantly improved the OS of previously treated patients with advanced non-squamous NSCLC [36]. The supplementary files of CheckMate 057 reported that among the patients with PD-L1 expression levels of $5 \%$ or higher, the objective response rate was $36 \%$, and the median OS was 18.1 months. However, among the patients with PD-L1 expression levels of $1 \%$ or lower, the objective response rate was only $10 \%$, and the median OS was only 9.7 months. Another randomized controlled trial, Keynote 001, reported that among patients with at least $50 \%$ of tumor cells expressing PD-L1 who received the anti-PD-1 monoclonal antibody pembrolizumab, the objective response rate was $45.3 \%$, which means that nearly half of the patients had tumor shrinkage by at least $30 \%$; however, in patients with less than $1 \%$ of tumor cells expressing PD-L1, the objective response rate was only $10.7 \%$ [37]. Because of the high predictive role of PDL1 expression, pembrolizumab was approved for patients with PD-L1-positive, advanced NSCLC in 2015. A phase 2 study revealed that PD-L1 expression levels were positive correlated with the efficacy of the anti-PD-L1 monoclonal antibody atezolizumab in NSCLC [38]. For promising clinical benefits may be associated with PD-L1 expression level in early stage treatment, it is pivotal to detecting 
PD-L1 expression by tumor cell as predictive maker for anti-PD-1/PD-L1 monoclonal antibodies treatment or as prognostic factor for poor survival in NSCLC patients.

In terms of histologic type, similar results were reported by Velcheti et al., who found that PD-L1 expression was associated with squamous cell carcinoma [23]. Another study showed that PD-L1 expression was not only associated with adenocarcinoma but also with the degree of differentiation and node metastasis [27]. However, a meta-analysis revealed that none of clinicopathologic characteristics, including sex, smoking status, tumor stage, node metastasis, TNM stage, differentiated degree and histological type was associated with PD-L1 expression in NSCLC [26]. We found no significant difference between smoking status and PD-L1 expression, but considering smoking data in our study was incomplete, so we did not show the smoking data here. A larger sample size with more patients may provide more convincing data.

Furthermore, we found that in patients with nonsquamous NSCLC, the OS was longer in those without PD-L1 expression than in those with PD-L1 expression. In contrast, there were no significant differences in different subgroup analyses according to female sex, tumor stage pT1, pT2, or pT4, or node metastasis. Subgroup analyses revealed that OS was more favorable in those without PD-L1 expression than in those with PD-L1 expression among males, but not among females. Cigarette smoking may be one reason of the difference between genders. Smoking is the number one risk factor for lung cancer and it directly contributes to cancer deaths in men more than in women in previous study [39]. The favorable OS in those without PD-L1 patients is observed in TNM stage I/II, III/IV disease and tumor stage pT3, but not in tumor stage pT1, pT2, or pT4 or node metastasis. This may be related to the relatively small sample size in these subgroups in present study. The statistical significance of these differences would be remarkable with a larger sample size. No significant difference in the proportion of squamous carcinoma was observed between the groups with and without PD-L1 expression, although this finding may have been different with longer follow-up or a larger sample size. Our results verified the expression of PD-L1 by tumor cells as a predictive maker in patients with squamous and non-squamous NSCLC. The phase 3 studies CheckMate 017 and CheckMate 057 have reported conflicting results regarding tumor PD-L1 expression and different responses to nivolumab in squamous and nonsquamous NSCLC patients. CheckMate 017 reported that OS, response rate, and progression-free survival were not correlative with PD-L1 expression levels in squamous-cell NSCLC patients, but CheckMate 057 reported contrary results in non-squamous NSCLC patients $[36,40]$.

MEDI4736 is a human IgG1 anti-PD-L1 monoclonal antibody being tested in an ongoing phase III trial in NSCLC. Atezolizumab (MPDL3280A), an engineered IgG anti-PD-L1 antibody, has also shown activity in ongoing phase III trial in NSCLC. Avelumab (MSB0010718C), a fully human anti-PD-L1 IgG1 antibody, currently being investigated in a phase III head-to-head trial of avelumab versus docetaxel in patients with NSCLC [41]. We anticipate promising

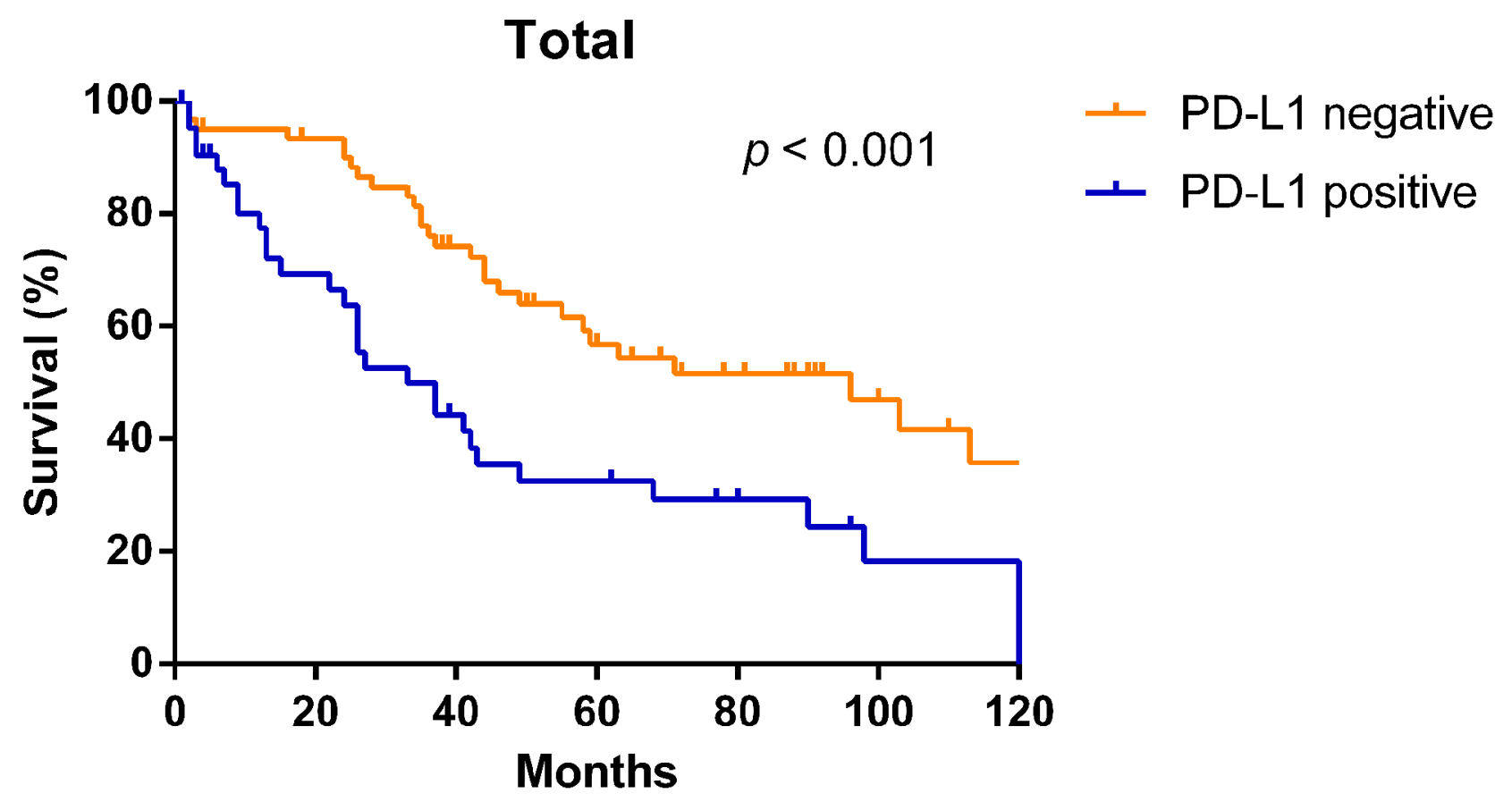

Figure 3: Kaplan-Meier overall survival curves according to PD-L1 expression in NSCLC patients. 
Table 3: The effect of clinicopathological characteristics and PD-L1 expression on overall survival

\begin{tabular}{|c|c|c|}
\hline Subtype & Hazard ratio $(95 \%$ CI) & $p$ Value \\
\hline \multicolumn{3}{|l|}{ Univariate analysis } \\
\hline \multicolumn{3}{|l|}{ Sex } \\
\hline Female & 1 & \\
\hline Male & $2.256(1.275-3.993)$ & 0.005 \\
\hline \multicolumn{3}{|l|}{ Age (in years) } \\
\hline$<60$ & 1 & \\
\hline$\geq 60$ & $1.046(0.622-1.761)$ & 0.865 \\
\hline \multicolumn{3}{|l|}{ TNM Stage } \\
\hline $\mathrm{I} / \mathrm{II}$ & 1 & \\
\hline III/IV & $2.770(1.635-4.693)$ & $<0.0001$ \\
\hline \multicolumn{3}{|l|}{ Tumor stage } \\
\hline pT1 & 1 & \\
\hline pT2 & $2.495(0.971-6.414)$ & 0.058 \\
\hline pT3 & $3.626(1.335-9.850)$ & 0.012 \\
\hline \multicolumn{3}{|l|}{ Node metastasis } \\
\hline $\mathrm{pN} 0$ & 1 & \\
\hline $\mathrm{pN} 1 / \mathrm{pN} 2$ & $4.116(2.308-7.341)$ & $<0.0001$ \\
\hline \multicolumn{3}{|l|}{ Histologic type } \\
\hline Non-squamous cell carcinoma & 1 & \\
\hline Squamous cell carcinoma & $1.754(1.024-3.004)$ & 0.041 \\
\hline \multicolumn{3}{|l|}{ Differentiation degree } \\
\hline Poorly differentiated & 1 & \\
\hline Moderately differentiated & $0.969(0.492-1.908)$ & 0.927 \\
\hline Highly differentiated & $0.199(0.044-0.906)$ & 0.037 \\
\hline \multicolumn{3}{|l|}{ PD-L1 expression } \\
\hline Negative & 1 & \\
\hline Positive & $2.281(1.355-3.840)$ & 0.002 \\
\hline \multicolumn{3}{|l|}{ Multivariate analysis } \\
\hline \multicolumn{3}{|l|}{ Sex } \\
\hline Female & 1 & \\
\hline Male & $2.236(1.236-4.047)$ & 0.008 \\
\hline \multicolumn{3}{|l|}{ TNM Stage } \\
\hline I / II & 1 & \\
\hline III / IV & $2.416(1.402-4.164)$ & 0.001 \\
\hline \multicolumn{3}{|l|}{ Histologic type } \\
\hline Non-squamous cell carcinoma & 1 & \\
\hline Squamous cell carcinoma & $1.128(0.635-2.006)$ & 0.681 \\
\hline \multicolumn{3}{|l|}{ PD-L1 expression } \\
\hline Negative & 1 & \\
\hline Positive & $2.568(1.459-4.520)$ & 0.001 \\
\hline
\end{tabular}


results from these studies of anti-PD-L1 monoclonal antibodies.

Although NSCLC patients have favorable clinical benefits from blocking the PD-1/PD-L1 pathway, certain issues must still be considered. The most important is that different score systems and different tricks of immunohistochemical technology maybe lead to different results. Furthermore, anti-PD-L1 monoclonal antibodies used for testing PD-L1 expression may lack sensitivity and yield false-negative results, and there is no uniform standard at present. In addition, the expression of PDL1 is very dynamic, and its uneven distribution in tumor tissue might lead to false-negative results [42-45]. Compared with other detection methods, we evaluated PD-L1 expression in tumor tissues with a standard and credible IHC protocol and reliable histochemistry score (H-score) system, which involved the percentage of positive tumor cells and the intensity of staining in tissue sections.

A standardized method of detecting PDL1expression maybe provide support for patients who are initially diagnosed with primary NSCLC by allowing for early anti-PD-1 or anti-PD-L1 monoclonal antibody immunotherapy, thus improving treatment efficacy and managing cost. Although the current method of detecting
PD-L1 is not as precise as EGFR test, the prospects of PD-L1 as a prognostic factor for poor survival are encouraging.

Efforts were made to conduct sound and rigorous research, but our study had some limitations. First, we obtained several interesting results using samples from 108 patients, but the results will need to be validated with a larger sample size. Second, we retrospectively collected all the information, rather than performing a prospective study. Third, PD-L1 expression was assessed with only IHC, but other detection methods are needed to verify the results.

In conclusion, the current study demonstrated that PD-L1 expression is an independent prognostic factor for poor survival in NSCLC patients, especially those with non-squamous NSCLC. We expect to develop an optimized method of detecting PD-L1 expression in tumor cells to validate PD-L1 as an accurate predictor for anti-PD-1/PD-L1 monoclonal antibody treatment. We anticipate that the anti-tumor efficacy of anti-PD-1/PD-L1 monoclonal antibodies will be strengthened and survival in NSCLC patients will be improved.

A
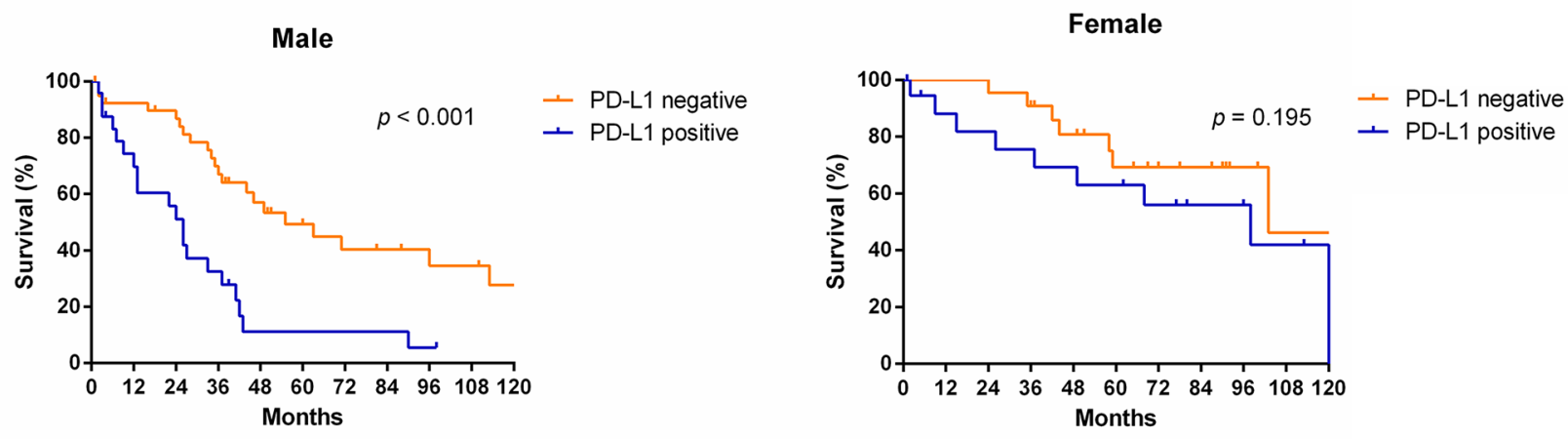

B
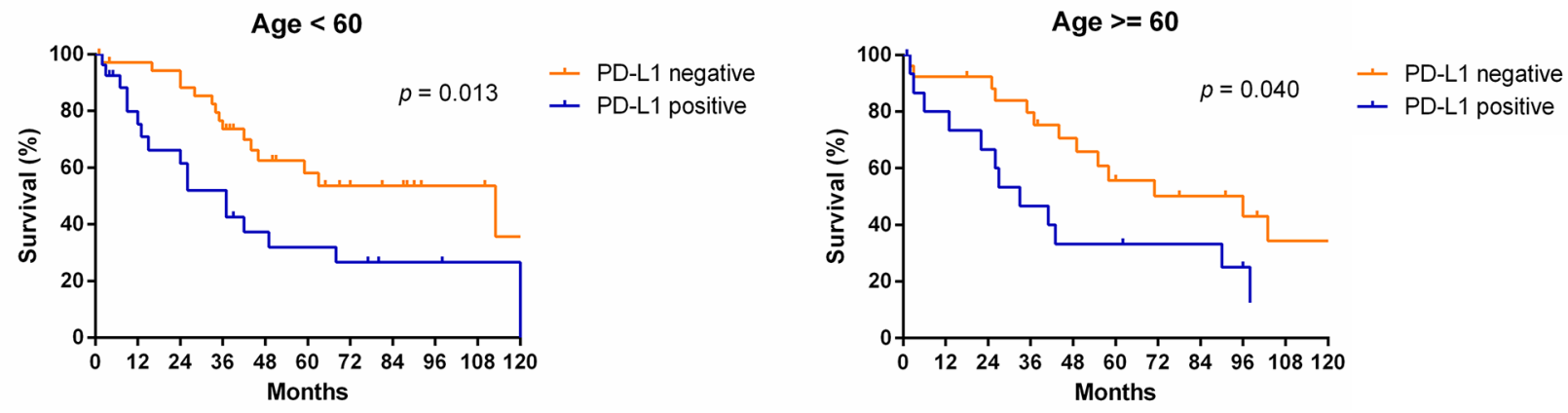

Figure 4: Survival analyses of NSCLC patients with and without PD-L1 expression in subgroups, including, including sex (A) and age (B). 
A
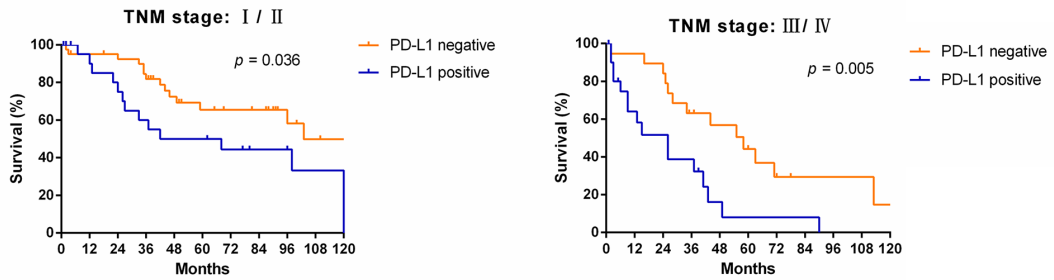

B
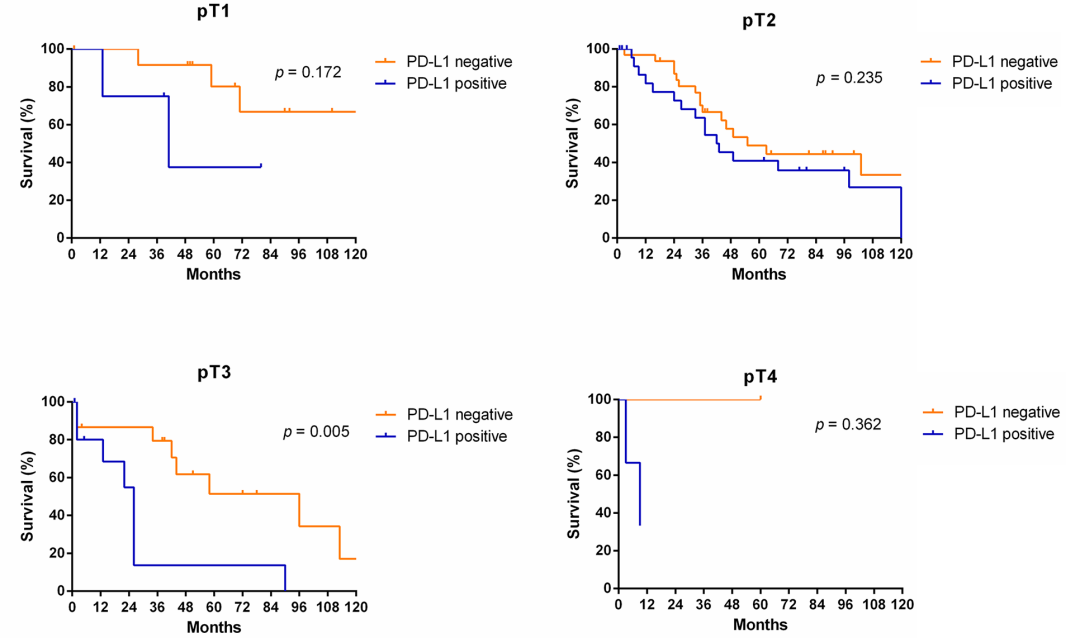

C
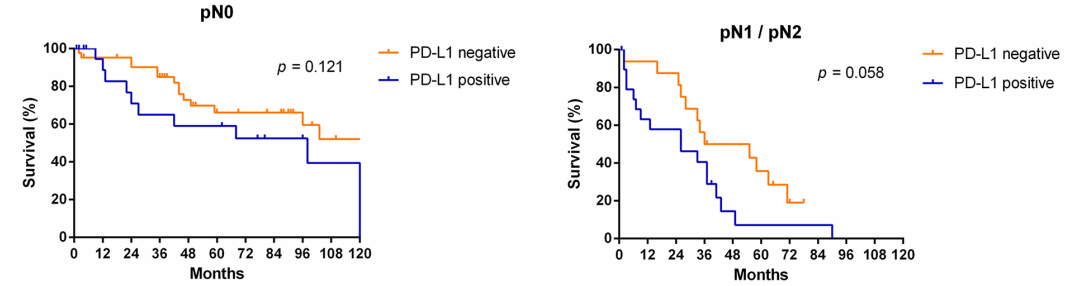

Figure 5: Survival analyses of NSCLC patients with and without PD-L1 expression in subgroups, including TNM stage (A), tumor stage (B) and node metastasis (C).

A
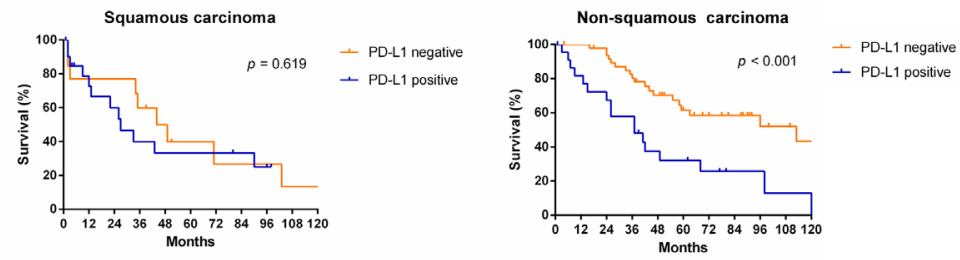

B
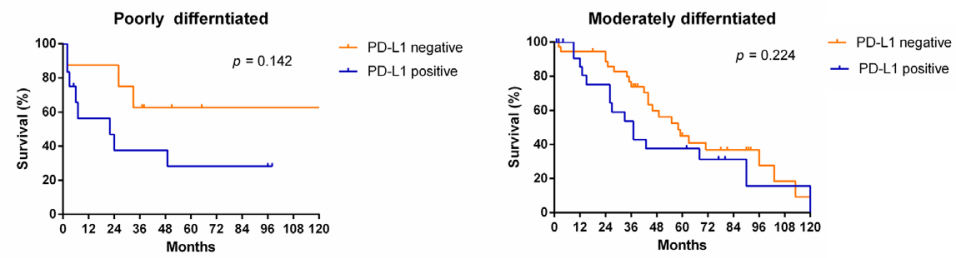

Figure 6: Survival analyses of NSCLC patients with and without PD-L1 expression in subgroups, including histologic type (A) and differentiated degree (B). 


\section{MATERIALS AND METHODS}

\section{Patients and samples}

This study included 108 patients who underwent tumor resection or palliative surgery for a primary tumor that was histologically confirmed as primary NSCLC between 2002 and 2012 at the Fifth Affiliated Hospital of Sun Yat-sen University. From their medical records, we retrieved and recorded patients' clinical data, such as sex, age, histologic type, and TNM stage (using the 7th UICC TNM Staging System of lung cancer). All of the patients were carefully monitored after initial treatment. Expert pathologists at the hospital re-reviewed hematoxylineosin-stained slides from all cases, and corresponding formalin-fixed, paraffin-embedded specimens were retrieved, rendering $2-\mu \mathrm{m}$-thick pathological sections mounted on glass slides.

\section{Immunohistochemistry}

PD-L1 IHC was performed using the commercial rabbit monoclonal antibody E1L3N (\#13684, Cell Signaling Technology, Danvers, USA). Tissue sections were deparaffinized in xylene and a subsequent ethanol series was used to rehydrate them. The sections were unmasked with antigen retrieval buffer (MVS-0099, Maxim EDTA buffer, $\mathrm{pH}$ 8.0) in an autoclave for $10 \mathrm{~min}$ at $120^{\circ} \mathrm{C}$. To block endogenous peroxidase activity, the sections were treated with $0.3 \%$ hydrogen peroxide for 30 min. and subsequently washed with phosphate-buffered saline. After being washed with phosphate-buffered saline, the sections were incubated with the PD-L1 antibody at a 1:200 dilution overnight at $4^{\circ} \mathrm{C}$. The sections were then washed three times with wash buffer for 5 min each time. The secondary antibody of the EliVision Plus kit detection system and the enhanced polymer 3, 3'diaminobenzidine detection kit (Maxim Biotech, Fuzhou, China) were used according to the manufacturer's instructions. After staining, the sections were washed in distilled water and dehydrated in graded alcohol. Finally, the sections were mounted with coverslips.

\section{Assessment of PD-L1 expression}

All of the stained sections were scored in five randomly selected areas containing tumor cells, which showed membranous and cytoplasmic staining. The percentage of positive tumor cells was graded on a scale of 0-4: $0(<1 \%)$, $1(1-10 \%) ; 2$ (11-50\%); 3, (51-70\%); and 4 (> 70\%). The intensity of staining was scored as follows: 0 (no staining), 1 (weak staining), 2 (moderate staining), and 3 (strong staining). The $\mathrm{H}$-score, ranging from 0 to 12 , was calculated by multiplying the percentage of positive tumor cells by the intensity of staining on the tissue sections. The $\mathrm{H}$-scores were categorized as follows: 0 : negative (-), 1-4: weak positive (+), 5-8: moderately positive $(++), 9-12$ : strong positive $(+++)$.

\section{Statistical analyses}

Each clinicopathologic characteristic was evaluated using Pearson's chi-squared test or Fisher's exact test (categorical variables). OS was measured from the date of the initial operation until the date of death or last follow-up. The Kaplan-Meier method and log-rank test were applied to assess OS. Univariate Cox regression proportional hazards analysis was used to assess clinicopathologic characteristics significantly related to OS with HRs and 95\% CIs. Multivariate Cox proportional hazards analysis was performed to determine whether PD-L1 expression is an independent prognostic factor. A two-sided $p$ value of $<0.05$ was considered statistically significant. Several variables were unknown; thus, their implications were not assessed. All statistical analyses were performed using SPSS 20 software (IBM, Armonk, NY).

\section{ACKNOWLEDGMENTS}

This research was supported by the National Natural Science Foundation of China (81500030, 81560403) and the Natural Science Foundation of Guangdong Province (2016A030313272, 2016A030313277).

\section{CONFLICTS OF INTEREST}

The authors declare no competing financial interests.

\section{REFERENCES}

1. Siegel R, Naishadham D, Jemal A. Cancer statistics, 2012. CA Cancer J Clin. 2012; 62:10-29.

2. Vesely MD, Kershaw MH, Schreiber RD, Smyth MJ. Natural innate and adaptive immunity to cancer. Annu Rev Immunol. 2011; 29:235-271.

3. Pardoll DM. The blockade of immune checkpoints in cancer immunotherapy. Nat Rev Cancer. 2012; 12:252-264.

4. Jadus MR, Natividad J, Mai A, Ouyang Y, Lambrecht N, Szabo S, Ge L, Hoa N, Dacosta-Iyer MG. Lung cancer: a classic example of tumor escape and progression while providing opportunities for immunological intervention. Clin Dev Immunol. 2012; 2012:160724.

5. Phan GQ, Yang JC, Sherry RM, Hwu P, Topalian SL, Schwartzentruber DJ, Restifo NP, Haworth LR, Seipp CA, Freezer LJ, Morton KE, Mavroukakis SA, Duray PH, et al. Cancer regression and autoimmunity induced by cytotoxic $\mathrm{T}$ lymphocyte-associated antigen 4 blockade in patients with metastatic melanoma. Proc Natl Acad Sci U S A. 2003; 100:8372-8377.

6. Leach DR, Krummel MF, Allison JP. Enhancement of antitumor immunity by CTLA-4 blockade. Science. 1996; 271:1734-1736. 
7. Hodi FS, O'Day SJ, McDermott DF, Weber RW, Sosman JA, Haanen JB, Gonzalez R, Robert C, Schadendorf D, Hassel JC, Akerley W, van den Eertwegh AJ, Lutzky J, et al. Improved survival with ipilimumab in patients with metastatic melanoma. N Engl J Med. 2010; 363:711-723.

8. Freeman GJ, Long AJ, Iwai Y, Bourque K, Chernova T, Nishimura H, Fitz LJ, Malenkovich N, Okazaki T, Byrne MC, Horton HF, Fouser L, Carter L, et al. Engagement of the PD-1 immunoinhibitory receptor by a novel B7 family member leads to negative regulation of lymphocyte activation. J Exp Med. 2000; 192:1027-1034.

9. Keir ME, Butte MJ, Freeman GJ, Sharpe AH. PD-1 and its ligands in tolerance and immunity. Annu Rev Immunol. 2008; 26:677-704.

10. Dong H, Zhu G, Tamada K, Chen L. B7-H1, a third member of the B7 family, co-stimulates T-cell proliferation and interleukin-10 secretion. Nat Med. 1999; 5:1365-1369.

11. Tseng SY, Otsuji M, Gorski K, Huang X, Slansky JE, Pai SI, Shalabi A, Shin T, Pardoll DM, Tsuchiya H. B7-DC, a new dendritic cell molecule with potent costimulatory properties for T cells. The Journal of experimental medicine. 2001; 193:839-846.

12. Latchman Y, Wood CR, Chernova T, Chaudhary D, Borde M, Chernova I, Iwai Y, Long AJ, Brown JA, Nunes R, Greenfield EA, Bourque K, Boussiotis VA, et al. PD-L2 is a second ligand for PD-1 and inhibits T cell activation. Nat Immunol. 2001; 2:261-268.

13. Muenst S, Schaerli AR, Gao F, Daster S, Trella E, Droeser RA, Muraro MG, Zajac P, Zanetti R, Gillanders WE, Weber WP, Soysal SD. Expression of programmed death ligand 1 (PD-L1) is associated with poor prognosis in human breast cancer. Breast Cancer Res Treat. 2014; 146:15-24.

14. Zheng Z, Bu Z, Liu X, Zhang L, Li Z, Wu A, Wu X, Cheng X, Xing X, Du H, Wang X, Hu Y, Ji J. Level of circulating PD-L1 expression in patients with advanced gastric cancer and its clinical implications. Chin J Cancer Res. 2014; 26:104-111.

15. Chae YK, Pan A, Davis AA, Raparia K, Mohindra NA, Matsangou M, Giles FJ. Biomarkers for PD-1/PD-11 blockade therapy in non-small-cell lung cancer: is PD-L1 expression a good marker for patient selection? Clin Lung Cancer. 2016; 17:350-361.

16. Zhang Y, Zhang J, Xu K, Xiao Z, Sun J, Xu J, Wang J, Tang Q. PTEN/PI3K/mTOR/B7-H1 signaling pathway regulates cell progression and immuno-resistance in pancreatic cancer. Hepatogastroenterology. 2013; 60:1766-1772.

17. Wu CT, Chen WC, Chang YH, Lin WY, Chen MF. The role of PD-L1 in the radiation response and clinical outcome for bladder cancer. Sci Rep. 2016; 6:19740.

18. Heeren AM, Punt S, Bleeker MC, Gaarenstroom KN, van der Velden J, Kenter GG, de Gruijl TD, Jordanova ES. Prognostic effect of different PD-L1 expression patterns in squamous cell carcinoma and adenocarcinoma of the cervix. Mod Pathol. 2016; 29:753-63.
19. Choueiri TK, Fay AP, Gray KP, Callea M, Ho TH, Albiges L, Bellmunt J, Song J, Carvo I, Lampron M, Stanton ML, Hodi FS, McDermott DF, et al. PD-L1 expression in nonclear-cell renal cell carcinoma. Ann Oncol. 2014; 25:2178-2184.

20. Merelli B, Massi D, Cattaneo L, Mandala M. Targeting the PD1/PD-L1 axis in melanoma: biological rationale, clinical challenges and opportunities. Crit Rev Oncol Hematol. 2014; 89:140-165.

21. Iwai Y, Ishida M, Tanaka Y, Okazaki T, Honjo T, Minato $\mathrm{N}$. Involvement of PD-L1 on tumor cells in the escape from host immune system and tumor immunotherapy by PD-L1 blockade. Proc Natl Acad Sci U S A. 2002; 99:12293-12297.

22. Cooper WA, Tran T, Vilain RE, Madore J, Selinger CI, Kohonen-Corish M, Yip P, Yu B, O'Toole SA, McCaughan BC, Yearley JH, Horvath LG, Kao S, et al. PD-L1 expression is a favorable prognostic factor in early stage non-small cell carcinoma. Lung Cancer (Amsterdam, Netherlands). 2015; 89:181-188.

23. Velcheti V, Schalper KA, Carvajal DE, Anagnostou VK, Syrigos KN, Sznol M, Herbst RS, Gettinger SN, Chen L, Rimm DL. Programmed death ligand-1 expression in nonsmall cell lung cancer. Lab Invest. 2014; 94:107-116.

24. Wang A, Wang HY, Liu Y, Zhao MC, Zhang HJ, Lu ZY, Fang YC, Chen XF, Liu GT. The prognostic value of PD-L1 expression for non-small cell lung cancer patients: a metaanalysis. Eur J Surg Oncol. 2015; 41:450-456.

25. Gandini S, Massi D, Mandala M. PD-L1 expression in cancer patients receiving anti PD-1/PD-L1 antibodies: a systematic review and meta-analysis. Crit Rev Oncol Hematol. 2016; 100:88-98.

26. Pan ZK, Ye F, Wu X, An HX, Wu JX. Clinicopathological and prognostic significance of programmed cell death ligand1 (PD-L1) expression in patients with non-small cell lung cancer: a meta-analysis. J Thorac Dis. 2015; 7:462-470.

27. Mu CY, Huang JA, Chen Y, Chen C, Zhang XG. High expression of PD-L1 in lung cancer may contribute to poor prognosis and tumor cells immune escape through suppressing tumor infiltrating dendritic cells maturation. Med Oncol. 2011; 28:682-688.

28. Thompson RH, Kuntz SM, Leibovich BC, Dong H, Lohse CM, Webster WS, Sengupta S, Frank I, Parker AS, Zincke H, Blute ML, Sebo TJ, Cheville JC, Kwon ED. Tumor $\mathrm{B} 7-\mathrm{H} 1$ is associated with poor prognosis in renal cell carcinoma patients with long-term follow-up. Cancer Res. 2006; 66:3381-3385.

29. Hino R, Kabashima K, Kato Y, Yagi H, Nakamura M, Honjo T, Okazaki T, Tokura Y. Tumor cell expression of programmed cell death-1 ligand 1 is a prognostic factor for malignant melanoma. Cancer. 2010; 116:1757-1766.

30. Zhang Y, Wang L, Li Y, Pan Y, Wang R, Hu H, Li H, Luo $\mathrm{X}$, Ye T, Sun Y, Chen H. Protein expression of programmed 
death 1 ligand 1 and ligand 2 independently predict poor prognosis in surgically resected lung adenocarcinoma. Onco Targets Ther. 2014; 7:567-573.

31. Gao Q, Wang XY, Qiu SJ, Yamato I, Sho M, Nakajima Y, Zhou J, Li BZ, Shi YH, Xiao YS, Xu Y, Fan J. Overexpression of PD-L1 significantly associates with tumor aggressiveness and postoperative recurrence in human hepatocellular carcinoma. Clin Cancer Res. 2009; 15:971-979.

32. Wu C, Zhu Y, Jiang J, Zhao J, Zhang XG, Xu N. Immunohistochemical localization of programmed death-1 ligand-1 (PD-L1) in gastric carcinoma and its clinical significance. Acta Histochem. 2006; 108:19-24.

33. Nomi T, Sho M, Akahori T, Hamada K, Kubo A, Kanehiro H, Nakamura S, Enomoto K, Yagita H, Azuma M, Nakajima Y. Clinical significance and therapeutic potential of the programmed death-1 ligand/programmed death-1 pathway in human pancreatic cancer. Cancer Res. 2007; 13:2151-2157.

34. Hamanishi J, Mandai M, Iwasaki M, Okazaki T, Tanaka Y, Yamaguchi K, Higuchi T, Yagi H, Takakura K, Minato N, Honjo T, Fujii S. Programmed cell death 1 ligand 1 and tumor-infiltrating CD8+ $\mathrm{T}$ lymphocytes are prognostic factors of human ovarian cancer. Proc Natl Acad Sci U S A. 2007; 104:3360-3365.

35. Wu P, Wu D, Li L, Chai Y, Huang J. PD-L1 and Survival in solid tumors: a meta-analysis. PLoS One. 2015; 10:e0131403.

36. Borghaei H, Paz-Ares L, Horn L, Spigel DR, Steins M, Ready NE, Chow LQ, Vokes EE, Felip E, Holgado E, Barlesi F, Kohlhaufl M, Arrieta O, et al. Nivolumab versus docetaxel in advanced nonsquamous non-small-cell lung cancer. N Engl J Med. 2015; 373:1627-1639.

37. Herbst RS, Baas P, Kim DW, Felip E, Pérez-Gracia JL, Han JY, Molina J, Kim JH, Arvis CD, Ahn MJ, Majem M, Fidler MJ, de Castro G, et al. Pembrolizumab versus docetaxel for previously treated, PD-L1-positive, advanced non-smallcell lung cancer (KEYNOTE-010): a randomised controlled trial. Lancet. 2016; 387:1540-1550.
38. Rosenberg JE, Hoffman-Censits J, Powles T, van der Heijden MS, Balar AV, Necchi A, Dawson N, O'Donnell $\mathrm{PH}$, Balmanoukian A, Loriot Y, Srinivas S, Retz MM, Grivas P, et al. Atezolizumab in patients with locally advanced and metastatic urothelial carcinoma who have progressed following treatment with platinum-based chemotherapy: a single-arm, multicentre, phase 2 trial. Lancet. 2016; 387:1909-1920.

39. Shopland DR, Eyre HJ, Pechacek TF. Smoking-attributable cancer mortality in 1991: is lung cancer now the leading cause of death among smokers in the United States? J Natl Cancer Inst. 1991; 83:1142-1148.

40. Brahmer J, Reckamp KL, Baas P, Crino L, Eberhardt WE, Poddubskaya E, Antonia S, Pluzanski A, Vokes EE, Holgado E, Waterhouse D, Ready N, Gainor J, et al. Nivolumab versus docetaxel in advanced squamous-cell non-small-cell lung cancer. N Engl J Med. 2015; 373:123-135.

41. Santarpia M, Giovannetti E, Rolfo C, Karachaliou N, Gonzalez-Cao M, Altavilla G, Rosell R. Recent developments in the use of immunotherapy in non-small cell lung cancer. Expert Rev Respir Med. 2016; 10:781-798.

42. Ilie M, Hofman V, Dietel M, Soria JC, Hofman P. Assessment of the PD-L1 status by immunohistochemistry: challenges and perspectives for therapeutic strategies in lung cancer patients. Virchows Arch. 2016; 468:511-525.

43. Kerr KM, Hirsch FR. Programmed death ligand-1 immunohistochemistry: friend or foe? Arch Pathol Lab Med. 2016; 140:326-331.

44. Kerr KM, Tsao MS, Nicholson AG, Yatabe Y, Wistuba, II, Hirsch FR. Programmed death-ligand 1 immunohistochemistry in lung cancer: in what state is this art? J Thorac Oncol. 2015; 10:985-989.

45. Lisberg A, Garon EB. The value of PD-L1 testing in nonsmall-cell lung cancer. JAMA Oncol. 2016 Mar 17. doi: 10.1001/jamaoncol.2016.0043. [Epub ahead of print]. 